\title{
GAS DIFFUSION AND FRACTIONATION IN CLATHRATED ICE-CORE SAMPLES
}

\author{
(Abstract) \\ by \\ J. Ocampo \\ (Laboratoire de Glaciologie et de Géophysique de l'Environnement, \\ B.P. 96, 38402 St Martin d'Hères Cédex, France)
}

\begin{abstract}
The evolution of gas content from clathrated ice is very sensitive to pressure and to storage temperature. As such substances are likely to be found in deep Antarctic ice and the Greenland ice sheet (Miller 1969, Shoji and Langway 1982), the influence of clathrate formation and incomplete back-diffusion on the measured air composition was investigated.

We have undertaken laboratory studies on the kinetics of formation and decomposition of clathrate hydrates of air and carbon dioxide. The kinetics were found to be controlled mainly by the self-diffusion of water molecules. The clathrate structure being of type II (Davidson and others 1984), the diffusion of guest molecules and the role of auxiliary gases was studied.

A bubble-relaxation model is presented for air-hydrate inclusions in fresh ice cores. It takes into account the diffusion constant for desorption of clathrates and the mechanical relaxation of the bulk ice. The increasing pressure and the initially low bubble surface are factors which limit the rate of decomposition. The rate of decomposition was compared with the natural bubble
\end{abstract}

relaxation measured in deep ice cores (Gow and Williamson 1975).

Fractionation was also observed through the formation and decomposition of mixed hydrates. The diffusion control of the recrystallization process affects this fractionation.

On the basis of this study we make some recommendations for the analysis of deep ice-core samples.

\section{REFERENCES}

Davidson D W, Handa Y P, Ratcliffe C I, Tse J S, Powell B M 1984 The ability of small molecules to form clathrate hydrates of structure II. Nature 311(5982): $142-143$

Gow A J, Williamson T 1975 Gas inclusions in the Antarctic ice sheet and their glaciological significance. Journal of Geophysical Research 80(36): 5101-5108

Miller S L, 1969 Clathrate hydrates of air in Antarctic ice. Science 165(3892): 489-490

Shoji H, Langway C C Jr 1982 Air hydrate inclusions in fresh ice core. Nature 298(5874): 548-550

\section{ISOTOPE MEASUREMENTS IN AN ICE CORE FROM A TEMPERATE ALPINE GLACIER (VERNAGTFERNER, AUSTRIA)}

\section{(Abstract)}

\author{
by
}

\section{H. Oerter, H. Moser, W. Rauert and W. Stichler}

(Gesellschaft für Strahlen- und Umweltforschung mbH München (GSF), Institut für Radiohydrometrie, D-8042, Neuherberg, Ingolstädter Landstraße 1, Federal Republic of Germany)

and

O. Reinwarth

(Kommission für Glaziologie der Bayerischen Akademie der Wissenschaften, D-8000 München 22, Marstallplatz 8, Federal Republic of Germany)

\section{ABSTRACT}

In 1979 ice-core drilling was carried out in the accumulation area of the temperate Alpine glacier Vernagtferner (Ötztaler Alpen, Austria). The cores are among the few cores from temperate glaciers in the eastern Alps. Encouraged by the results of the isotope analysis $\left({ }^{2} \mathrm{H}\right.$, ${ }^{18} \mathrm{O},{ }^{3} \mathrm{H}$ ) of this core, which proved that it was possible to detect the annual layering in the firn, a second drilling operation was undertaken in 1983. One core (IV) was org/10.3189/S0260305500004614 Published online by Cambridge University Press drilled near the 1979 drilling site, in order to check the results from the first core. A second one (VI) was drilled near the equilibrium line, in order to obtain information on the isotope content of the ice body near the ablation area. In addition, the electrical conductivity was also measured. The paper presents the measurements of the $80 \mathrm{~m}$ core VI of 1983: ${ }^{18} \mathrm{O}$ and ${ }^{2} \mathrm{H}$ profile, together with the calculated deuterium excess $d$, as well as the ${ }^{3} \mathrm{H}$ profile, which gives evidence of the 1952-63 nuclear-bomb tests already at a 
depth of between approximately 4.5 and $7 \mathrm{~m}$ below the surface. There is a discrepancy of about $0.5 \mathrm{~m}$ between the maximum ${ }^{3} \mathrm{H}$ peak and the peak of an in-situ gamma-ray log. The latter would coincide better with the ${ }^{18} \mathrm{O}$ layering, so that there remains an uncertainty of 3 years in dating the upper 20 years of accumulation. The annual variations in the isotope content remain recognizable, especially with the aid of the deuterium excess. Thus it is possible to compare the thickness of the annual layers of the earlier core I (in the accumulation area) with that of the later core VI (which is located at a lower elevation) and see how the layers become thinner. Comparing cores I and IV, possible sources of changes in the isotope content, such as melt-water flow, are discussed.

\title{
THE DILEMMA OF THE RAPID VARIATIONS IN $\mathrm{CO}_{2}$ IN GREENLAND ICE CORES
}

\section{(Abstract)}

by

\author{
H. Oeschger, A. Neftel, T. Staffelbach and B. Stauffer
}

(Universität Bern, Physikalisches Institut, $\mathrm{CH}-3012$ Bern, Sidlerstraße 5, Switzerland)

\section{ABSTRACT}

Stauffer and others (1984) observed in the Greenland ice core from Dye $3 \mathrm{CO}_{2}$ variations between low values in the range of $180-200 \mathrm{ppm}$ volume and higher values in the range of $240-260 \mathrm{ppm}$ volume, over a period tentatively dated to $30000-40000$ years B.P. The low values are observed in samples with low $\delta^{18} \mathrm{O}$, high particle and chemical impurity contents, representing precipitation from periods of cold climate; the higher $\mathrm{CO}_{2}$ concentrations are measured in samples which reflect warm climatic conditions because of their high $\delta^{18} \mathrm{O}$ and low impurity contents. The change from one climatic state to the other seems to occur within less than a century. This unexpected observation has received considerable attention from the scientific community. First, the question was posed whether the rapid $\mathrm{CO}_{2}$ variations do indeed reflect atmospheric $\mathrm{CO}_{2}$-concentration changes or whether they are caused by the interaction of gases with chemical constituents in the ice matrix. Secondly, carbon-cycle modellers searched for a mechanism in the carbon system which could produce such rapid changes in atmospheric $\mathrm{CO}_{2}$. Here we try to answer the first question.

Arguments in favour of an atmospheric origin of the $\mathrm{CO}_{2}$ variations are: $\mathrm{CO}_{2}$ measurements on an ice core from Siple Station, Antarctica, show a monotonous increase over the past 250 years, from values around $280 \mathrm{ppm}$ volume to values overlapping closely with the direct atmospheric data which have been obtained since 1958 (Neftel and others 1985). Thus a consistent picture of the anthropogenic $\mathrm{CO}_{2}$ increase has been obtained which is compatible with estimates of the man-made $\mathrm{CO}_{2}$ emissions and with the carbon-cycle calculations of the airborne fraction of these emissions.

In addition, convincing $\mathrm{CO}_{2}$-concentration data have been obtained, from two ice cores from Greenland and four ice cores from Antarctica, for the transition from low (180-200 ppm volume) late-Wisconsin values to the higher (260-300 ppm volume) Holocene values. In spite of considerable differences in temperature, fabrics and chemical properties, the Wisconsin $\mathrm{CO}_{2}$-concentration values for ice cores from different locations lie in a narrow band. The Holocene values show a greater scatter; in particular, the values obtained for the Dye 3 core are significantly higher than those for the other cores. This can be explained by a relatively high temperature, which leads to melting in summer. In refrozen melt layers, $\mathrm{CO}_{2}$ is enriched in comparison with the other air gases. On the basis of these observations we conclude that melt layers are the main factor which can lead to considerable deviations in the $\mathrm{CO}_{2}$ concentration of the air occluded in ice cores from that of the atmosphere at ice formation.

To test if the melt-layer effect was the cause of the rapid changes in $\mathrm{CO}_{2}$ concentration which were observed in the Dye 3 core, increments of the Camp Century core from north Greenland were measured for $\mathrm{CO}_{2}$; they show similarly rapid Wisconsin $8^{18} \mathrm{O}$ and $\mathrm{CO}_{2}$ changes, though they are less abrupt than in the Dye 3 core. At Camp Century the present mean annual temperature is $4.5^{\circ} \mathrm{C}$ lower than at Dye 3, and during the Wisconsin the temperature difference was even greater, as indicated by the $\delta^{18} \mathrm{O}$ values. Because even for Holocene ice in the Camp Century core the melt-layer effect on the $\mathrm{CO}_{2}$ concentration is relatively small, we exclude any similar significant effect on the Wisconsin ice. On the basis of the Greenland ice-core information alone, therefore, we have no indication that the rapid Wisconsin $\mathrm{CO}_{2}$ variations do not represent an atmospheric phenomenon.

Arguments against an atmospheric origin for the rapid $\mathrm{CO}_{2}$ variations stem from detailed analyses of the ice core from Byrd Station, Antarctica. Observation of the increase in anthropogenic atmospheric $\mathrm{CO}_{2}$ in both hemispheres indicates that within a few years $\mathrm{CO}_{2}$ becomes well mixed throughout the atmosphere. Thus the $\mathrm{CO}_{2}$ variations observed in the Greenland core should also appear in the Antarctic core increments which represent corresponding periods. A thorough $\mathrm{CO}_{2}$ study was performed on a Byrd Station core fraction which, according to a tentative time-scale (personal communication from C.U. Hammer, 1987), corresponds to the time interval 5000-55000 years B.P. (Fig.1). In what follows, we briefly discuss the data in

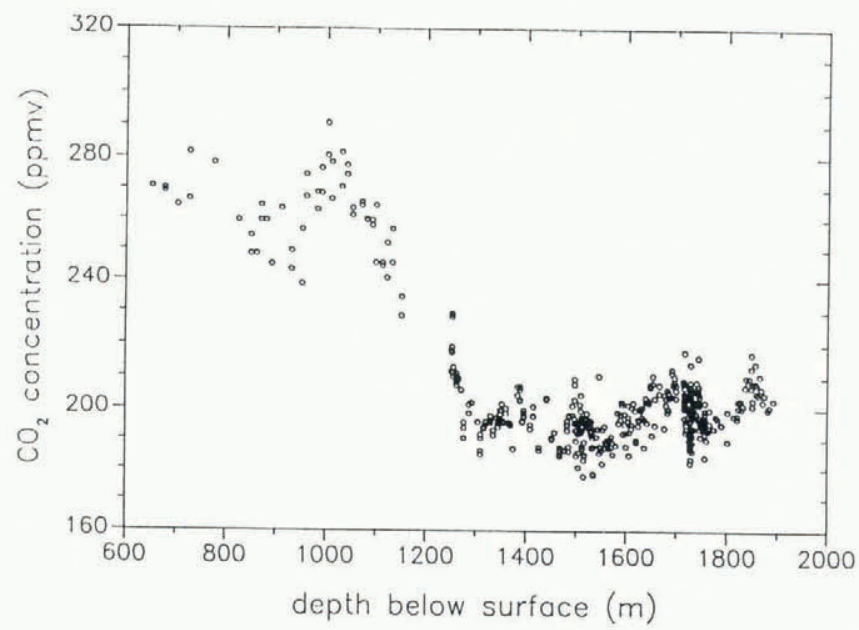

Fig.1. Atmospheric $\mathrm{CO}_{2}$-concentration data measured on Byrd Station core, Antarctica, plotted versus depth (Neftel and others, in press). 